\title{
Fabrication of Thermal Plasma Sprayed NiTi Coatings Possessing Functional Properties
}

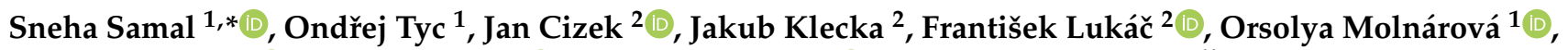 \\ Esther de Prado $^{1}{ }^{\mathbb{D}}$, Zdeněk Weiss ${ }^{1}{ }^{\mathbb{D}}$, Jaromír Kopeček ${ }^{1} \mathbb{1}$, Luděk Heller ${ }^{1,3}$, Petr Šittner ${ }^{1,3}$ and Tomáš Chráska ${ }^{2}$ \\ 1 Institute of Physics of the Czech Academy of Sciences, Na Slovance, 18200 Praha 8, Czech Republic; \\ tyc@fzu.cz (O.T.); molnarova@fzu.cz (O.M.); prado@fzu.cz (E.d.P.); weissz@fzu.cz (Z.W.); \\ kopecek@fzu.cz (J.K.); heller@fzu.cz (L.H.); sittner@fzu.cz (P.Š.) \\ 2 Institute of Plasma Physics of the Czech Academy of Sciences, Za Slovankou, \\ 18200 Prague 8, Czech Republic; cizek@ipp.cas.cz (J.C.); klecka@ipp.cas.cz (J.K.); lukac@ipp.cas.cz (F.L.); \\ chraskat@ipp.cas.cz (T.C.) \\ 3 Nuclear Physics Institute of the Czech Academy of Sciences, 25068 Husinec-Rez, Czech Republic \\ * Correspondence: samal@fzu.cz
}

check for updates

Citation: Samal, S.; Tyc, O.; Cizek, J.; Klecka, J.; Lukáč, F.; Molnárová, O.; de Prado, E.; Weiss, Z.; Kopeček, J.; Heller, L.; et al. Fabrication of Thermal Plasma Sprayed NiTi Coatings Possessing Functional Properties. Coatings 2021, 11, 610. https://doi.org/10.3390/ coatings 11050610

Academic Editor: Cecilia Bartuli

Received: 23 April 2021

Accepted: 17 May 2021

Published: 20 May 2021

Publisher's Note: MDPI stays neutral with regard to jurisdictional claims in published maps and institutional affiliations.

Copyright: (c) 2021 by the authors. Licensee MDPI, Basel, Switzerland. This article is an open access article distributed under the terms and conditions of the Creative Commons Attribution (CC BY) license (https:/ / creativecommons.org/licenses/by/ $4.0 /)$.

\begin{abstract}
Thick NiTi shape memory alloy coatings (300-500 $\mu \mathrm{m})$ were produced on graphite and AISI 304 substrates by radio frequency inductively-coupled plasma spray technology (RF-ICP) from feedstock NiTi powders. Their microstructure as well as chemical and phase composition were characterized and a methodology for the characterization of functional shape memory properties of the thick coatings was developed. The coatings exhibited cubic to monoclinic martensitic transformation and shape memory effect. The presented results prove that NiTi coatings with functional thermomechanical properties can be easily produced on structural materials by RF-ICP. Further optimization will be needed to prepare NiTi coatings with better microstructural and chemical homogeneity.
\end{abstract}

Keywords: NiTi; shape memory alloy; thick coating; thermal plasma spraying; functional behavior

\section{Introduction}

NiTi shape memory alloys (SMA) are functional materials offering unique thermomechanical functional properties, in particular the shape memory effect, superelasticity, high damping, or actuation capability in contrast to conventional metals and alloys [1-3]. These properties derive from martensitic transformation between B2 cubic austenite and B19' monoclinic martensite, the progress of which can be controlled in a reversible manner by the change of temperature and/or mechanical stress. Moreover, since NiTi alloys exhibit excellent corrosion resistance and biocompatibility, they have been successfully utilized in production of medical devices and tools $[3,4]$.

NiTi alloy components are conventionally prepared by machining from semi-products, such as rods, sheets, and wires, or cut from ingots prepared via casting or powder metallurgy technologies. Cold working, heat treatment and shape setting are used to set the functional properties and shape of the NiTi components. Besides these, alternative production routes have been reported in the literature, including thin film growth by magnetron sputtering [5], 3D printing by lasers [6], spark plasma sintering (SPS) [7] or self-propagating high temperature synthesis (SHS) [8]. Despite their successful use in the production of NiTi components for selected specific applications, none of these methods became widely commercialized yet.

Thermal plasma spraying enables preparation of material coatings via a single-step process, in which the material is melted and solidifies under controllable atmospheric conditions $[9,10]$. Indeed, early trials $[11,12]$ have proven that it is possible to prepare thermally sprayed NiTi coatings, but little information was provided on their quality, particularly with regard to their functional properties. 
Radio frequency inductively coupled plasma (RF-ICP) method is one of the efficient thermal plasma spray techniques in which the energy is supplied by electric current triggered by electromagnetic induction. This method provides a high energy output within a controlled zone of the plasma jet in the controlled-atmosphere chamber. During the process, the feedstock powder particles are fed axially into the plasma jet. The high temperature in the plasma leads to their melting, forming liquid droplets that are accelerated toward the substrate by the plasma momentum. Upon an impact with the substrate, the molten droplets flatten, conform to the underlying material, and rapidly solidify, thereby forming thin lamellae called splats. With each pass of the plasma torch, a layer of specific thickness is formed, consisting of the individual splats. Multiple torch passes can be employed to reach the desired thickness, typically $50-1000 \mu \mathrm{m}$.

In this work, we propose that thermal plasma spray technology can be used as another alternative technology route to fabricate thick NiTi coatings with desired thickness and functional properties. Specifically, this paper aims at demonstrating the feasibility of the RF-ICP technology application to fabricate NiTi coatings with thicknesses of up to $500 \mu \mathrm{m}$, possessing functional SMA properties such as superelasticity or shape memory effect. The main advantage of this approach should be a rapid production of coatings orders-of-magnitude thicker than PVD, CVD coatings, as well as the potential to readily cover uneven or geometrically complex surfaces. The fabricated coatings were subjected to comprehensive characterization of microstructure, chemical and phase composition, as well as phase transformation. A specific testing methodology is further proposed herein for the characterization of the functional properties of the fabricated coatings.

\section{Materials and Methods}

\subsection{Materials}

Two commercial gas atomized NiTi powders having nominal chemical composition indicated as $55.5 \mathrm{wt} . \% \mathrm{Ni}$ and $44.5 \mathrm{wt} . \%$ Ti (corresponding to approximately 50.4 and 49.6 atomic \%) were chosen as the feedstock. The powders exhibited spherical morphology providing good flowability and hence sprayability (Figure 1).

Powder 1 showed a presence of small satellites attached to bigger particles; this is usually caused by a backflow of the gases in the atomization process but should not have any influence on the spray process. The average particle size distribution was measured using a laser device (Mastersizer 3000, Malvern, UK, Figure 1). Powder 1 possessed a rather broad distribution of 11-107 $\mu \mathrm{m}$ (D10-D90) and included a significant proportion of particles smaller than $1 \mu \mathrm{m}$. Contrary to this, Powder 2 ranged from $21-59 \mu \mathrm{m}$, i.e., an ideal range for thermal spray deposition using RF-ICP.

To demonstrate the flexibility of the RF-ICP method, two dissimilar materials were used as substrates: graphite (JAP Industries, Bystrice, Czech Republic) and AISI 304 stainless steel (Italinox, Prague, Czech Republic). The former had a cylindrical shape with a diameter of $60 \mathrm{~mm}$ and a height of $10 \mathrm{~mm}$, while the latter had a rectangular shape with dimensions of $60.6 \times 20 \times 3 \mathrm{~mm}^{3}$ (Figure 2). The chemical composition of the AISI 304 steel is given by the metallurgy standards as $0.07 \% \mathrm{C}, 17.5-19.5 \% \mathrm{Cr}, 8-10.5 \% \mathrm{Ni}, 2 \% \mathrm{Mn}$, $1 \% \mathrm{Si}$, with the impurities level limited to $0.11 \% \mathrm{~N}, 0.05 \% \mathrm{P}, 0.03 \% \mathrm{~S}$. 

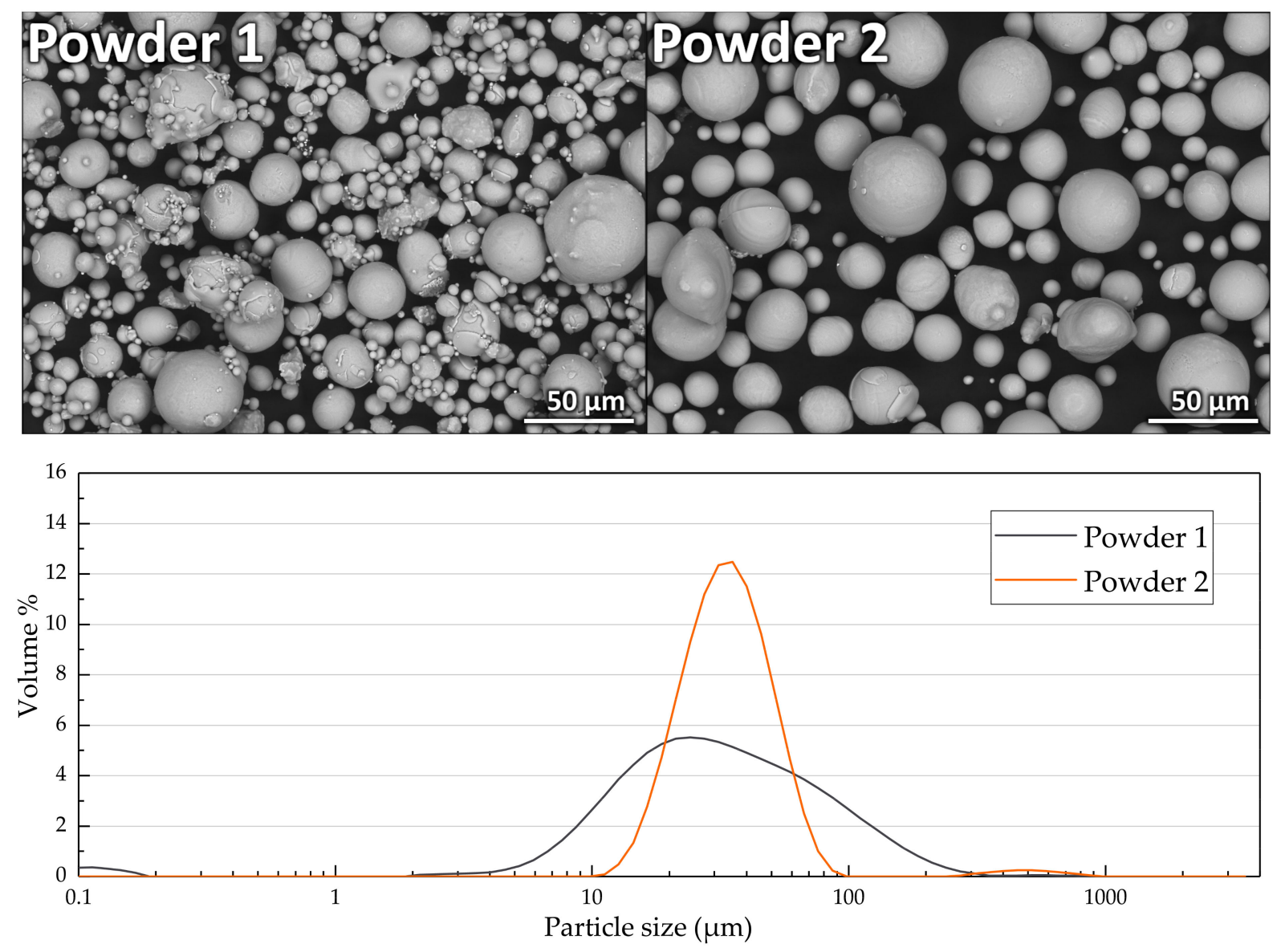

Figure 1. Spherical morphology of the gas atomized powders used to plasma spray the NiTi coatings and the average particle size distribution showing differences between the two powders.

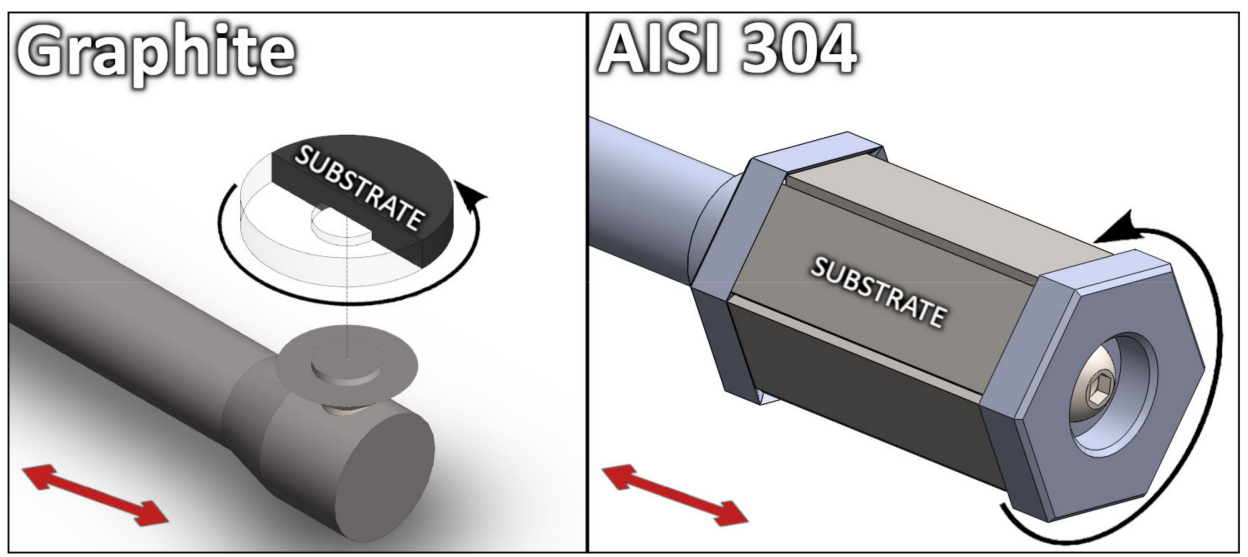

Figure 2. Two types of substrates and dedicated holders used in our study. Left shows a disc-shaped graphite substrate that revolved around the axis parallel to the spray direction. Right shows six rectangular stainless-steel substrates mounted on a water-cooled holder that revolved around its $x$-axis. In both cases, even thickness of the deposits was achieved by simultaneously moving the holders along the $x$-axis (denoted by red arrow; for the graphite disc, a value of $x=0$ corresponds to the center of the graphite disc positioned directly below the axis of the plasma torch).

\subsection{Samples Production}

TekSpray-15 RF-ICP plasma system (Tekna, Canada) was used for production of the NiTi coatings at Institute of Plasma Physics of the Czech Academy of Sciences in Prague, Czech Republic. Prior to the deposition, all substrates were cleaned in acetone 
to remove grease and impurities. The substrates were not grit blasted since standalone coatings were required in the following analyses stage. Immediately prior to the spraying, the substrates were pre-heated using the plasma jet (without material feeding) to aid in spreading behavior of the splats and thereby lower the porosity content, a well-established procedure demonstrated, e.g., in [13].

Three samples are presented in this paper. Given the Gaussian spatial distribution of the powder particles density within the plasma jet, it was necessary to compensate for it by a movement of the substrate holders to reach an even coating thickness. Two samples were sprayed using Powder 1 on the graphite substrates using a non-cooled holder (Figure 2). The substrates were placed below the plasma torch at a stand-off distance of $70 \mathrm{~mm}$ and revolved at $22 \mathrm{rpm}$ around the axis parallel to the spray direction during the spraying. The $x$-position (i.e., the horizontal distance between the center of the plasma jet and the center of the disc-shaped graphite substrate; red arrow in Figure 2) was held constant at $x=7 \mathrm{~mm}$ for Sample 1. In order to cover a larger area of the substrate, this was modified to $x=7,14$, and $20 \mathrm{~mm}$ (i.e., repeatedly switching between the three positions) during the deposition of Sample 2. The dwell times at each $x$-position were controlled to compensate for different peripheral speeds during the revolution. Further, to comprehend the different thermal input into Sample 2, a different spray scenario was also employed: while for Sample 1, a continuous spraying for $30 \mathrm{~s}$ was used (one torch pass), Sample 2 was sprayed in four torch passes, each lasting $45 \mathrm{~s}$; of these, $15 \mathrm{~s}$ was spraying of NiTi, and $30 \mathrm{~s}$ was an inter-pass cooling period. Secondly, the powder feed rate was doubled for Sample 2 , reaching $4.2 \mathrm{~g} / \mathrm{min}$ (cf. $2.1 \mathrm{~g} / \mathrm{min}$ for Sample 1, Table 1). Considering good thermal conductivity of graphite, both Samples 1 and 2 were sprayed at full torch power of $15 \mathrm{~kW}$.

Table 1. Experimental setup for RF-ICP deposition of three different type of NiTi coatings.

\begin{tabular}{cccccc}
\hline Sample & Substrate & NiTi Powder & Powder Feed Rate (g/min) & Torch Power (kW) & Coating Thickness (mm) \\
\hline Sample 1 & graphite & Powder 1 & 2.1 & 15 & 0.35 \\
Sample 2 & graphite & Powder 1 & 4.1 & 15 & 0.30 \\
Sample 3 & AISI 304 & Powder 2 & 4.5 & 12 & 0.50 \\
\hline
\end{tabular}

Powder 2 and stainless steel (AISI 304) substrates were used for Sample 3 production. Given the different thermal capacity and significantly lower melting point of the steel (as compared to graphite), a reduced torch power of $12 \mathrm{~kW}$ was used, and the substrates were mounted to another, in-house made, water-cooled holder, capable of holding up to six substrates (Figure 2). The holder is designed to allow revolving around the $x$-axis (cf. the holder for graphite substrates). During the revolution, its continuous linear movement along the $x$-axis (red arrow in Figure 2) at a speed $0.1 \mathrm{~mm} / \mathrm{s}$ was used to deposit the NiTi coating onto the AISI 304 steel substrates. The stand-off distance for Sample 3 was also $70 \mathrm{~mm}$ and the higher powder feed rate $(4.5 \mathrm{~g} / \mathrm{min}$, i.e., slightly higher than Sample 2) was used.

For all three samples, the chamber pressure was maintained at $103 \mathrm{kPa}$. Identical gas flows were used for the three runs: argon as sheath gas at $35 \mathrm{slpm}$ as well as powder carrier gas at $8 \mathrm{slpm}$ (the gas that brings the powder particles from the feeder into the plasma jet), and a mixture of argon and hydrogen as central gas (10 slpm and $3.6 \mathrm{slpm}$, respectively). Note that for the lower power value (12 kW for Sample 3), the flow of hydrogen was reduced to $2.6 \mathrm{slpm}$ to retain the plasma jet stability. The final thickness of the produced coating depends on the powder feed rate and number of torch passes. The key spray parameters used for production of Samples 1-3 are summarized in Table 1.

\subsection{Characterization Techniques}

The aim of the study was to show the RF-ICP technology as a potential method to produce thick NiTi coatings on structural materials. However, the development of a suitable and reliable methodology able to assess the SMA-related properties required 
standalone coatings, i.e., without the substrate material. Therefore, the fabricated coatings were removed from the substrates for such testing. Mechanical removing from the graphite substrates was aided by the thermal expansion mismatch between the two materials. Despite the absence of grit blasting, the adhesion of the NiTi coatings on the AISI 304 substrates was too high, and a simple mechanical approach could not be employed; instead, electric discharge cutting in a water-cooling medium was used.

The free-standing NiTi coatings were then prepared for metallographic observations using standard procedures (sequential grinding and polishing finished by using $0.05 \mu \mathrm{m}$ colloidal silica suspension). Their microstructure was characterized using FEI Quanta 3D Dual-Beam (FEI, Hillsboro, USA) and Tescan FERA 3 (Tescan, Brno, Czech Republic) scanning electron microscopes (SEM), the latter equipped with field emission cathode. The analyses were performed using either secondary electron imaging for topography or back scattered electrons for chemical Z contrast. The SEM images were further used for quantification of the coatings' porosity by image analysis (ImageJ software (version 1.8.0), three different areas per sample at two different SEM magnifications to improve the statistics reliability). Energy-dispersive X-ray spectroscopy (EDS) was carried out using EDAX system (EDAX, Mahwah, USA) with Octane Super $60 \mathrm{~mm}^{2}$ detector to determine the homogeneity of the chemical composition. The voltage used for the EDS analysis was $15 \mathrm{kV}$ to ensure the visibility of $\mathrm{K}$ line for $\mathrm{Ni}$. The phase and grain orientation distribution analysis was performed using electron back scattered diffraction method (EBSD) using the EDAX DigiView IV camera. The measurements were performed at $20 \mathrm{kV}$ acceleration voltage and a working distance of $15 \mathrm{~mm}$. The absorbed current under such setting is usually $1-2 \mathrm{nA}$. The used step size of mapping was $2 \mu \mathrm{m}$ in the top line and $0.5 \mu \mathrm{m}$ in bottom line. The chemical composition of the coatings was further analyzed using glow discharge-optical emission spectroscopy (GD-OES) [14] using GDA750 HR spectrometer (Spectruma GmbH., Hof, Germany) in a DC discharge in argon, with a 2.5-mm diameter anode at $800 \mathrm{~V}$ and $15 \mathrm{~mA}$. The phase composition was analyzed by X-ray diffraction using PANalytical $X^{\prime}$ Pert Pro diffractometer (Malvern, UK) with K $\alpha$ Co radiation using Fe filter. The phase identification was performed using the X'Pert High Score program which accessed the PDF-4 database of crystalline phases. Quantitative Rietveld refinement and Pawley mode in the Rietveld analysis was performed using TOPAS V3, aiming at the determination of austenite to martensite ratio and content of potential additional phases $[15,16]$.

In order to find out whether the produced coatings possess functional thermomechanical properties, several sample types were further laser-cut (Nd-YAG, $5 \mathrm{~W}$ power, cutting speed $100 \mathrm{~mm} / \mathrm{min}$ ) from the coatings. The transformation temperatures and functional behavior of the NiTi coatings were then investigated by several methods. To manifest the functionality, most of the results presented in this paper are shown for one of the samples only. Differential scanning calorimetry (DSC) using DSC 25 (TA Instruments, New Castle, USA) instrument at a scanning rate of $5 \mathrm{~K} / \mathrm{min}$ in the temperature range from -100 to $+100{ }^{\circ} \mathrm{C}$ (powders) and from -150 to $+150{ }^{\circ} \mathrm{C}$ (samples) was performed. For these tests, small samples were placed and measured in an Al crucible (weights from $13.3 \mathrm{mg}$ to $22.8 \mathrm{mg}$ ). The thermo-mechanical response was investigated by thermo-mechanical analysis (TMA) using TMA PT 1600 (Linseis, Selb, Germany). For that, deflection of $17 \times 5 \times 0.3 \mathrm{~mm}^{3}$ samples subjected to three-point bending was evaluated during cooling/heating in the maximum temperature range from -140 to $+150{ }^{\circ} \mathrm{C}$ under a constant load of $200 \mathrm{mN}$. Finally, the shape memory behavior of the NiTi coatings was tested by bending and tensile tests. The bending was carried out using Discovery DMA 850 tester (TA Instruments, New Castle, USA) at seven selected temperatures ranging from -50 to $+100{ }^{\circ} \mathrm{C}$. In these tests, a unified approach was followed: each $25 \times 5 \times 0.3 \mathrm{~mm}^{3}$ sample was heated to $100{ }^{\circ} \mathrm{C}$ first, then cooled to the respective testing temperature, loaded to $1000 \mathrm{MPa}$ (static load), unloaded and heated to $100{ }^{\circ} \mathrm{C}$ again to return to the original state. For both the heating and cooling, a rate of $5^{\circ} \mathrm{C} / \mathrm{min}$ was used. The tensile tests were carried out using Instron 1362 tester (Instron, Norwood, USA) with a load cell capacity of $10 \mathrm{kN}$ using 
dog bone-shaped samples with the dimensions $25 \times 5 \times 0.3 \mathrm{~mm}^{3}$. A strain-controlled mode was used (strain rate of $0.011 / \mathrm{s}$ ) at a constant temperature of $20^{\circ} \mathrm{C}$. Three identical cycles comprising of loading, unloading, and a stress-free heating to $100{ }^{\circ} \mathrm{C}$ were used.

\section{Results and Discussion}

\subsection{Coatings Microstructure}

Given the differences in number of torch passes, the positioning of the substrates below the torch during the spraying, and the different feed rates used, the final thickness of the three coating samples ranged greatly, from 300-500 $\mu \mathrm{m}$ (Table 1, Figure 3).

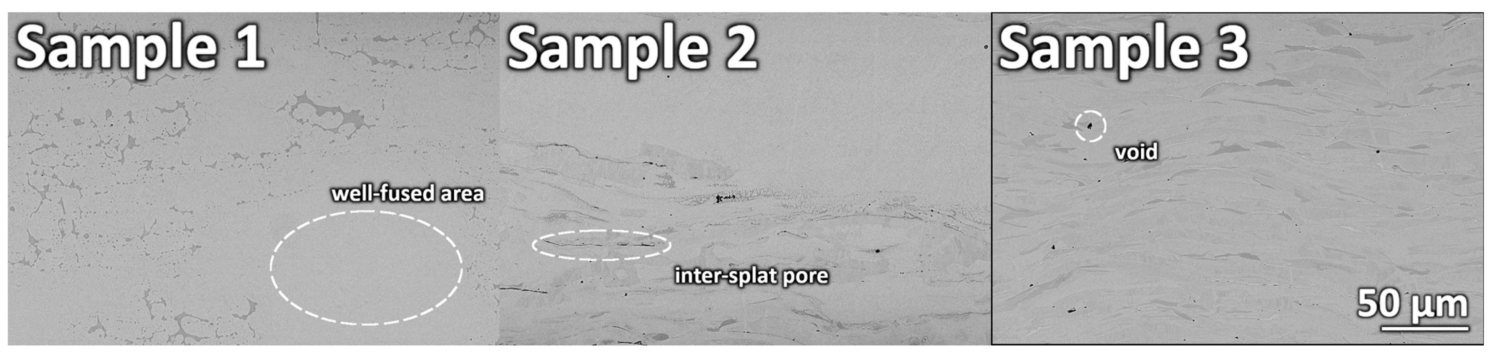

Figure 3. Microstructure of the RF-ICP sprayed NiTi coatings. The images microstructure differences stemming from different spray setup used for samples fabrication.

The three coatings possessed significantly different microstructures, ranging from fully remelted (Sample 1), to semi-remelted (Sample 2), to a layered pattern typical for thermally sprayed coatings (Sample 3). Such difference is linked to the different heat input experienced by the NiTi material in the spraying: the power of $15 \mathrm{~kW}$, spraying onto a stationary substrate (revolving only), and the low amount of material fed into the process $(2.1 \mathrm{~g} / \mathrm{min})$ all resulted into excessive of heat that caused remelting of the deposited coating. This was partially avoided for Sample 2, where the change in deposition layout and the increased amount of fed material (i.e., the plasma enthalpy distributed over a bigger mass) caused a formation of semi-molten, semi-layered structure (illustrated in Figure 3). The use of water-cooled holder and $12 \mathrm{~kW}$ of power resulted into formation of a layered structure consisting of individual splats, a feature typical for virtually all thermal spray processes (Sample 3). The layered microstructures (part of Sample 2 and entire Sample 3) contained some porosity. However, its level was rather negligible $(0.23 \%$ and $0.13 \%$, respectively, cf. $0.02 \%$ for Sample 1), confirming that the used torch powers of $12 \mathrm{~kW}$ and $15 \mathrm{~kW}$ are sufficient to melt the NiTi material. Infrequently, unmelted particles were observed in Sample 1 and Sample 2, a consequence of the rather wide particle size distribution of the feedstock Powder 1.

To further investigate the microstructure of the produced coatings in more detail, EBSD analysis of Sample 3 was carried out (Figure 4).

The results suggested an important phase inhomogeneity, with two types of regions present. Deeper in the coating (i.e., closer to where the interface with the substrate was before the separation), a ternary phase region of B2 austenite, B19' martensite, and intermetallic $\mathrm{NiTi}_{2}$ was observed. Interestingly, the martensite grains were significantly finer than the relatively large, micron-sized austenitic grains. The distribution of these phases was notably uneven and gradually changed from toward the free surface. At the very surface, a region with almost purely austenitic grains was present. As opposed to the former, this region was more uniform, also exhibiting elongation of austenitic grains in the direction parallel to the coating thickness. The existence of austenite and martensite regions are most likely a consequence of local inhomogeneity in the chemical composition or residual quenching stress arising inside the splats in the deposition. As a consequence, the upper coating layers are likely to exhibit martensitic transformation and functional properties, while the lower layers may not strongly contribute to such properties, lacking the transformability and functional behavior. 

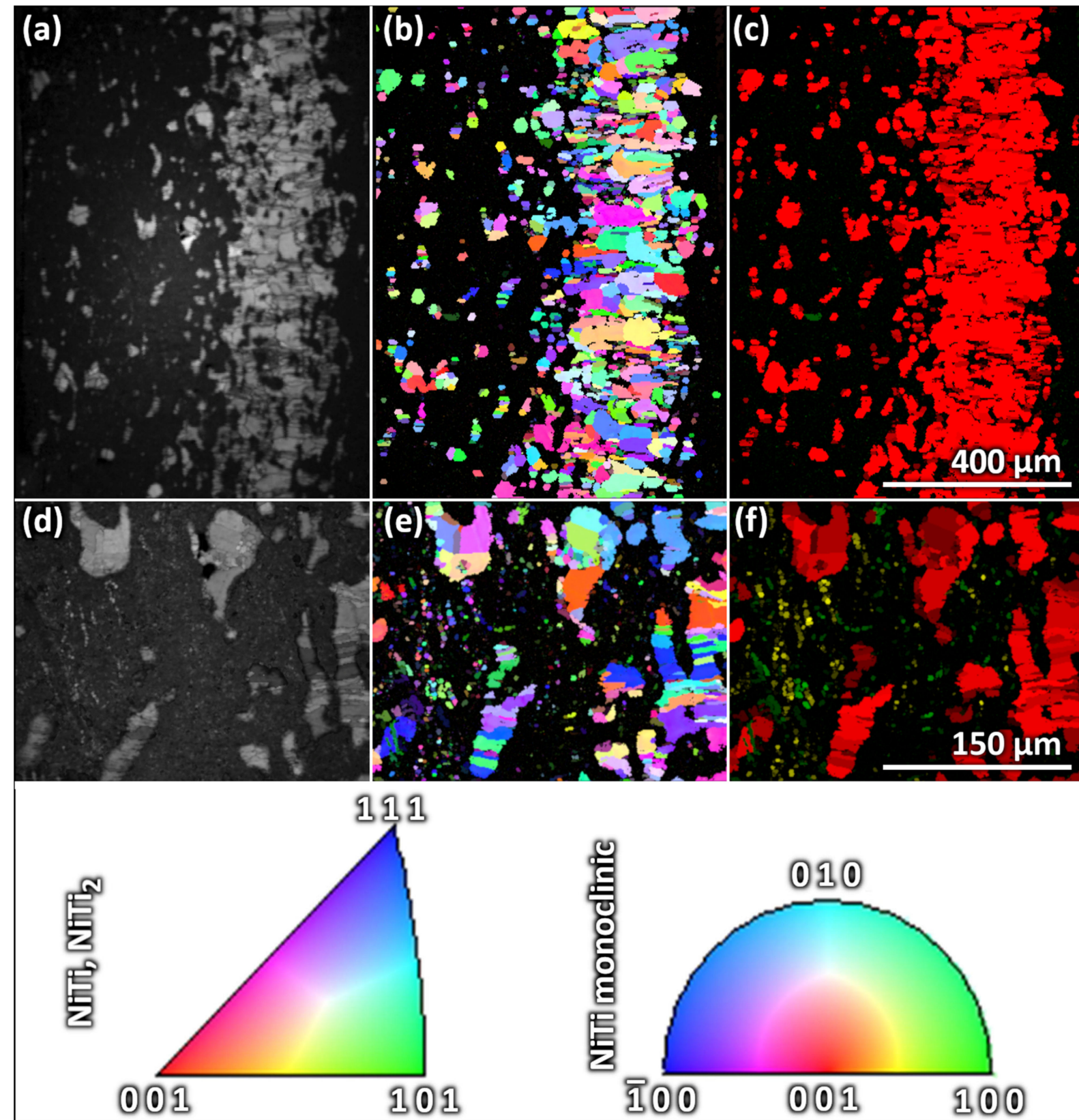

Figure 4. EBSD analysis of the produced NiTi coatings (Sample 3 shown for illustration). The top row is a global view of the coating, illustrating gradual distribution of relatively big austenite grains toward the free surface. (a) Image quality map of the entire area, (b) corresponding IPF map showing individual grains overlaid on the grayscale confidence index map, and (c) the corresponding phase map overlaid on the grayscale confidence index map. The bottom row is an enhanced detail showing smaller martensite and $\mathrm{NiTi}_{2}$ grains. (d) Image quality map of the enlarged area, (e) corresponding IPF map showing individual grains overlaid on the grayscale confidence index map, and (f) corresponding phase map overlaid on the grayscale confidence index map. In the phase maps, red, green, and yellow colors denote B2 austenite, B19' martensite, and $\mathrm{NiTi}_{2}$ phases, respectively. In the dark regions, the signal could not be analyzed (no Kikuchi bands, probably due to too fine microstructure). The legends in the IPF maps pertain to cubic symmetry phases (austenite, $\mathrm{NiTi}_{2}$ ), and martensite.

\subsection{Chemical Composition Analysis}

Ideally, the chemical composition of the deposited NiTi coatings needs to be approximately equiatomic to contain the desired B2 cubic austenite phase that exhibits functional thermomechanical behavior. That said, should the stoichiometric composition differ from that of the feedstock powder, the transformation temperatures may change dramatically. 
The global chemical composition of the three coatings evaluated by GD-OES technique is presented in Table 2.

Table 2. Compositional analysis of the NiTi materials. The composition of the Powder 1 was analyzed using atomic absorption analysis (AAS), while composition of Powder 2 was provided by the manufacturer. Composition of the coatings was determined by GD-OES with accuracy of 0.1 (all in wt.\%).

\begin{tabular}{ccc}
\hline Sample & Ni & Ti \\
\hline Powder 1 & 55.5 & 44.5 \\
Powder 2 & 55.5 & 44.5 \\
Sample 1 & 51.2 & 48.6 \\
Sample 2 & 48.8 & 50.4 \\
Sample 3 & 50.5 & 49.5 \\
\hline
\end{tabular}

In thermal spraying, a selective deposition phenomenon is frequently reported: given differences in inherent physical properties (such as, e.g., melting point), some elements are deposited easier than others, resulting in a change in their mutual ratio in the final coatings. Nevertheless, the global Ni/Ti ratio of the three produced samples differed from that of the feedstock powders only slightly and all were close to the ideal composition. The preservation of the composition probably stems from the fact that the used powder particles contained a solid solution of $\mathrm{Ni}$ and $\mathrm{Ti}$, as opposed to studies where a mere blend (mixture) of two powders was plasma sprayed (e.g., Swain et al. [17]). The Samples 1 and 2 contained low amounts of carbon $(0.03-0.78 \mathrm{wt} . \%)$, a consequence of diffusion process from the used graphite substrate. Despite the very limited content, its presence could have a partially detrimental effect on the shape memory properties of the coatings. No such contamination was found for Sample 3. Taking advantage of a controlled atmosphere during the RF-ICP process, no oxide content was detected in all three coatings, a major achievement as opposed to studies operating with atmospheric plasma sources [17].

The EDS mapping analysis (Figure 5) aided in understanding that the coatings were not strictly homogeneous in terms of their local $\mathrm{Ni}$ and Ti content and a limited partial segregation occurred. This effect was rather strong, and the content of Ni locally varied from $33-53 \mathrm{wt}$.\% (correspondingly, Ti content varied from 67-47 wt.\%). That said, composition of some regions neared that of NiTi, while there were also coating regions with composition closer to $\mathrm{NiTi}_{2}$.

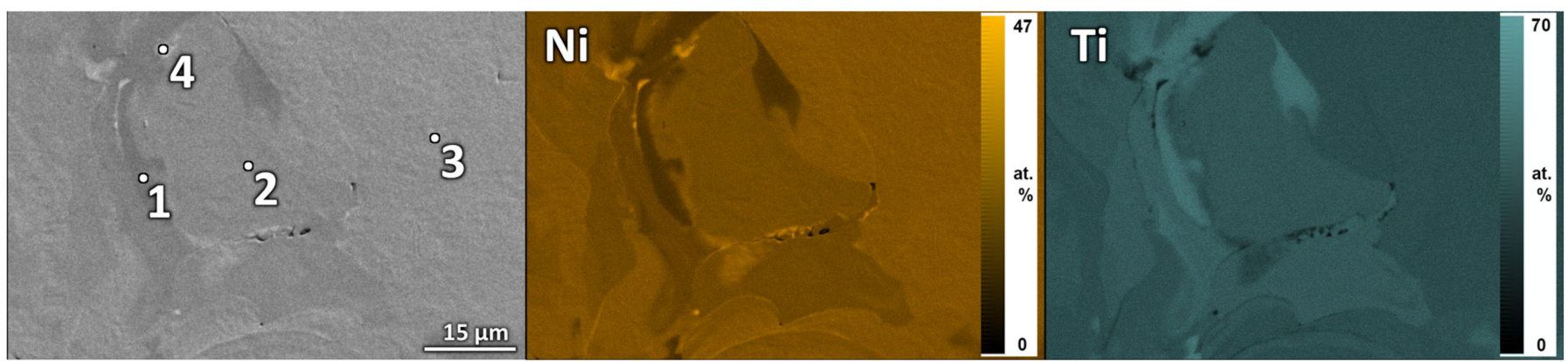

Figure 5. EDX elemental mapping of the NiTi coatings (Sample 3 shown for illustration) showing localized partial inhomogeneity in the relative content of $\mathrm{Ni}$ and Ti. The Ni:Ti ratio changed as much as from 33:67, to 44:56, to 48:52, to 53:47 (areas 1-4, respectively, all in wt.\%).

\subsection{Phase Analysis by X-ray Diffraction}

Despite the global chemical composition of the coatings nearing the ideal equiatomic, various phases could have appeared in the deposited coatings due to the high thermal input and non-equilibrium conditions the material is subjected to during its deposition. For 
the NiTi system, these could include the cubic B2 austenite phase, trigonal R-phase and/or monoclinic B19' martensite phase [17] as well as various intermetallic phases. The phase composition of the two NiTi powders and the three coatings produced using different process parameters was measured using $\mathrm{X}$-ray diffraction (Figure 6).

Table 3. Phase analysis of the NiTi materials by XRD (all in wt.\%).

\begin{tabular}{cccc}
\hline Sample & Austenite & Martensite & $\mathbf{N i T i}_{\mathbf{2}}$ \\
\hline Powder 1 & 19 & 81 & - \\
Powder 2 & 64 & 36 & - \\
Sample 1 & 21 & 69 & 10 \\
Sample 2 & 35 & 52 & 13 \\
Sample 3 & 41 & 48 & - \\
\hline
\end{tabular}

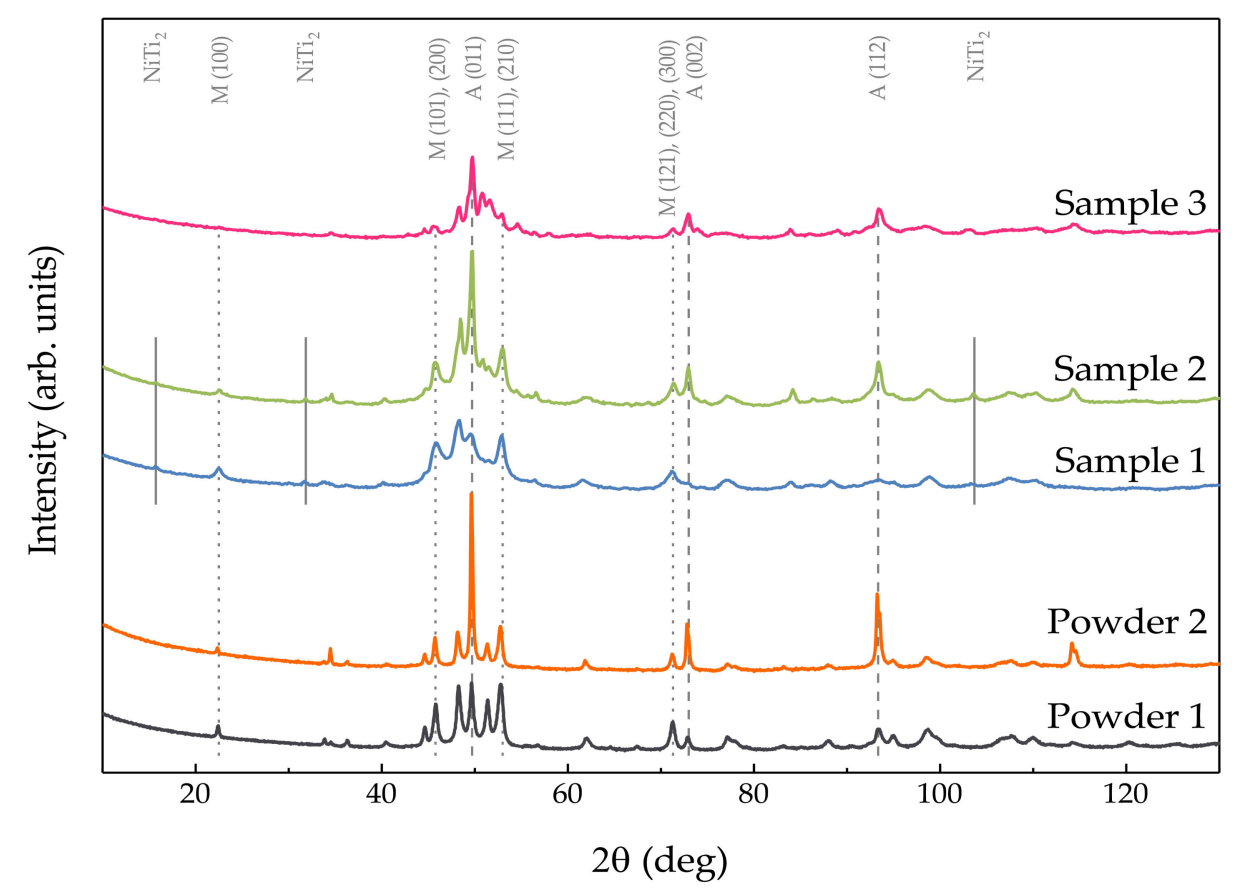

Figure 6. XRD patterns of the starting NiTi powders and the three Samples 1-3. A mix of austenite (some of its contributing peaks denoted by dashed gray vertical lines) and martensite (some of the contributing peaks denoted by dotted lines) was found in all samples. $\mathrm{NiTi}_{2}$ intermetallic phase was further found in S1 + S2 (peaks denoted by solid lines). For clarity, only selected major peaks are annotated in the graph. Please note that some peaks are actually a convoluted overlap of several peaks that may pertain to different $(\mathrm{hkl})$ reflections of even either of the three phases. The acquired patterns were processed using quantitative Rietveld refinement and Pawley mode in the Rietveld analysis, and all evidence a mixture of B2 austenite and B19' martensite phases (Table 3).

Despite the identical fabrication route of the two powders, their phase content showed a significant difference in the relative ratio of austenite to martensite ( 0.23 for Powder 1 and 1.78 for Powder 2). This is probably a consequence of the temperature conditions employed by the two manufacturers in the production phase. Unlike the powders, the XRD patterns collected for the three samples differed in their crystalline quality (i.e., size of coherently diffracting domains) and exhibited broadened and overlapped peaks, preferred orientation and also presence of intermetallic compounds (Figure 6). The A/M ratio differed from the powders and also among the three samples, reaching 0.30, 0.67, and 0.85 for Samples $1-3$, respectively. Such changes in the crystalline quality and the A/M ratios may have originated due to the non-equilibrium nature of the plasma spray process and the different employed spray scenarios, as well as a different substrate material in the case of Sample 
3, which cause a series of effects, such as distortion of the crystal lattice $[18,19]$, enhanced diffusion, and evolution of internal stresses. In accordance with the EBSD and EDX observations, the $\mathrm{NiTi}_{2}$ phase was detected in the coatings, as well as two other intermetallic phases in Sample $3\left(\mathrm{Ni}_{3} \mathrm{Ti}\right.$, and $\mathrm{Ni}_{3} \mathrm{Ti}_{4}$, both comprising approximately $11 \%$ content). As much as formation of secondary phases is a phenomenon inherently associated with high temperature thermal spray processes, the presence of NiTi-based intermetallics would partially deteriorate the functional properties and need to be addressed in future efforts. It is important to note that the presence of the texture and residual strain deteriorates the precision of the Rietveld refinement and Pawley mode in the Rietveld analysis quantification (by approximately $\pm 5 \%$ ) and so it is important to understand the recorded values against this information. The lattice parameter and phases of the NiTi includes B2 austenite (cubic, $\mathrm{Pm} \overline{3} m, a_{\mathrm{c}}=3.015 \AA$ ), B19' martensite (monoclinic, $\mathrm{P} 2_{1} / \mathrm{m}, \mathrm{a}_{\mathrm{m}}=2.889 \AA$, $\alpha_{\mathrm{m}}=90^{\circ}, \mathrm{b}_{\mathrm{m}}=4.622 \AA, \beta_{\mathrm{m}}=90^{\circ}, \mathrm{c}_{\mathrm{m}}=4.120 \AA, \gamma_{\mathrm{m}}=96.8^{\circ}$ ), and $\mathrm{NiTi}_{2}$ intermetallic (cubic, $\mathrm{Fm} \overline{3} m, \mathrm{a}=11.320 \AA$ ) [1]. Rietveld refinement was employed in order to determine the lattice parameters of the present phases which values are presented in Table 4. For the sake of comparison, the information regarding the feedstock powders is also included in the table.

Table 4. Crystal structure, lattice parameter for the powders and coating samples.

\begin{tabular}{ccccccc}
\hline $\begin{array}{c}\text { Phase Crystal Structure } \\
\text { (Space Group) }\end{array}$ & $\begin{array}{c}\text { Austenite } \\
\text { Cubic (Fm-3m) }\end{array}$ & \multicolumn{3}{c}{$\begin{array}{c}\text { Martensite Monoclinic } \\
(\mathbf{P 2 1} / \mathbf{m})\end{array}$} & $\begin{array}{c}\mathbf{N i T i}_{2} \mathbf{C u b i c} \\
\mathbf{( F d - 3 m )}\end{array}$ \\
\hline Lattice parameter & $a(\AA)$ & $a(\AA)$ & $\mathrm{b}(\AA)$ & $\mathrm{c}(\AA)$ & $\beta\left({ }^{\circ}\right)$ & $a(\AA)$ \\
Powder 1 & 3.013 & 4.634 & 4.130 & 2.892 & 97.063 & - \\
Powder 2 & 3.013 & 4.637 & 4.130 & 2.891 & 97.173 & - \\
Sample 1 & 3.016 & 4.649 & 4.124 & 2.900 & 97.400 & 11.380 \\
Sample 2 & 3.014 & 4.624 & 4.134 & 2.899 & 97.342 & 11.326 \\
Sample 3 & 3.011 & 4.658 & 4.117 & 2.885 & 97.241 & - \\
\hline
\end{tabular}

Our values are very close to those found in the literature for austenite and martensite phases of NiTi $[1,20,21]$ and intermetallic phases of $\mathrm{NiTi}_{2}[1,22,23]$. The small differences can be explained by, e.g., the internal residual stress, the inhomogeneity of the precursors' composition, and the overlapping between individual peaks.

\subsection{Martensitic Transformation upon Thermal Cycling}

The martensitic transformations in the NiTi materials triggered by thermal cycling were investigated by the DSC method (Figure 7). Single peaks observed upon heating (endothermal) and cooling (exothermal) of the materials evidence a progress of a single-step martensitic phase transformation, from the parent B2 cubic austenite to the monoclinic B19' martensite phase. The corresponding transformation temperatures were calculated from the transformation peaks (Table 5).

As opposed to the feedstock powders, the three produced NiTi coatings exhibited a notable upward shift of the transformation temperatures, approximately by $+30{ }^{\circ} \mathrm{C}$ (Figure 7). The peak in the cooling curve of Sample 3 presented in Figure 7 was ascribed to martensite phase. However, this may not be $100 \%$ correct as there is a potential ambiguity in determination between martensite and R-phase in this case. The observed temperature shift when translating from powder to the final coatings could be triggered by a range of factors. Some of these, such as compositional variation generated during the high temperature deposition, intermetallic phase formations, grain size, or even residual stress formation (a phenomenon typical for thermal spray processes), may indeed contribute towards the observed temperatures shift towards the higher end. The shift could be caused by the different chemical composition of the three coatings (slightly higher Ti content, Table 2) or even by the presence of the internal residual stresses. 


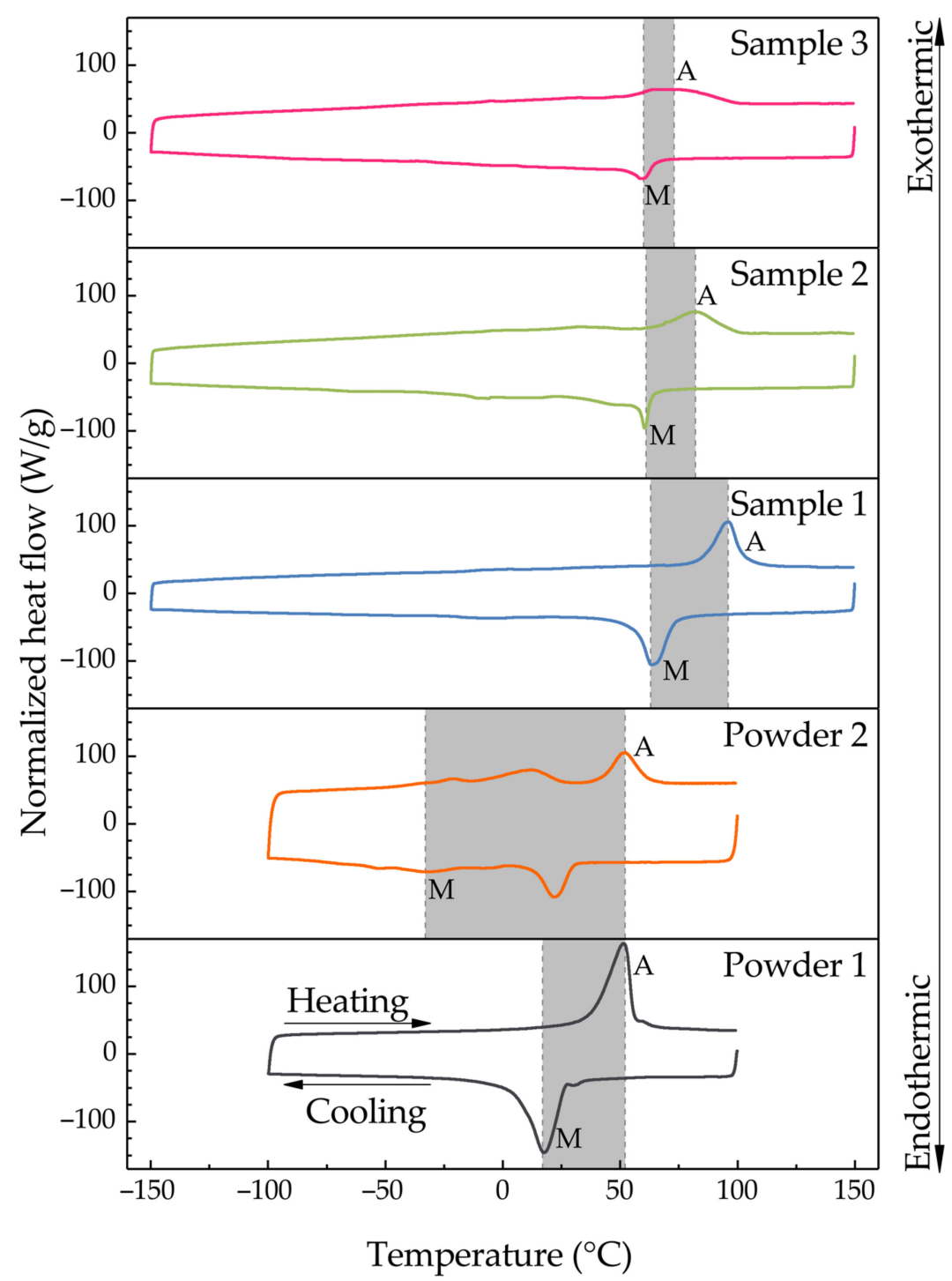

Figure 7. Differential scanning calorimetry analysis of the starting NiTi powders and the three Samples 1-3. Heating (upper part of every curve) and cooling (bottom part) were performed in the range of -100 to $+100{ }^{\circ} \mathrm{C}$ for Powders 1 and 2 and a maximum range of -150 to $150{ }^{\circ} \mathrm{C}$ for the samples. The $y$-axis represents endothermic/exothermic character of the changes. The peaks of austenite and martensite phases formation are denoted by letters (A, M), and for clarity, the austenite-martensite temperature range is highlighted in light gray color. The small gaps in the curves are caused by beginning/end of the respective measurement cycle.

Table 5. Transformation temperatures of the NiTi materials $\left(\right.$ all in $\left.{ }^{\circ} \mathrm{C}\right)$.

\begin{tabular}{ccccccc}
\hline Sample & Start & $\begin{array}{c}\text { Austenite } \\
\text { Peak }\end{array}$ & Finish & Start & $\begin{array}{c}\text { Martensite } \\
\text { Peak }\end{array}$ & Finish \\
\hline Powder 1 & 38 & 52 & 56 & 27 & 17 & 5 \\
Powder 2 & 43 & 52 & 62 & -23 & -33 & -43 \\
Sample 1 & 84 & 96 & 103 & 73 & 63 & 53 \\
Sample 2 & 66 & 82 & 99 & 64 & 61 & 58 \\
Sample 3 & 48 & 73 & 100 & 65 & 60 & 52 \\
\hline
\end{tabular}

Another method used for evaluation of the transformation temperatures was TMA, performed in the bending mode from -140 to $+150{ }^{\circ} \mathrm{C}$ here (Figure 8 ). 


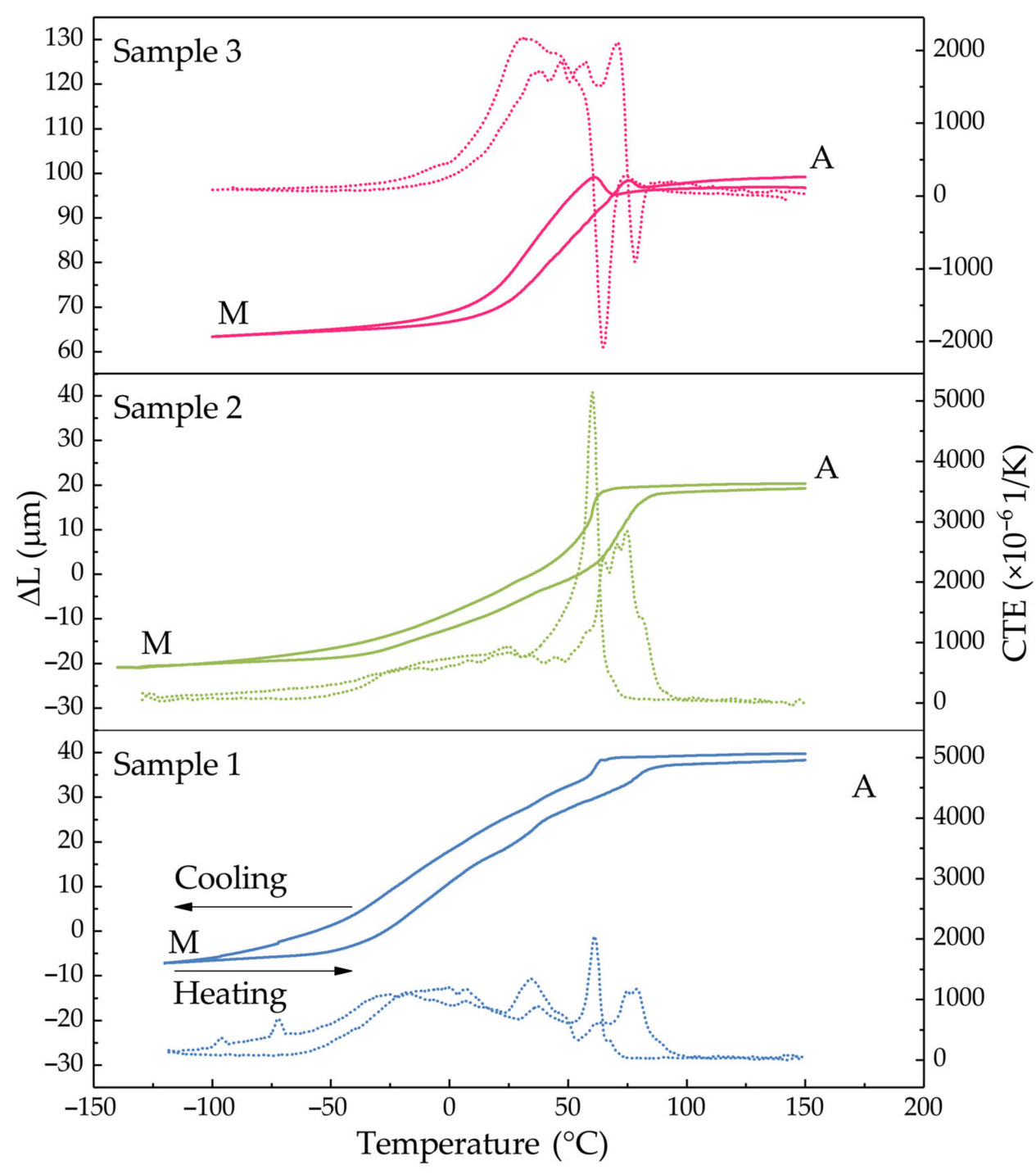

Figure 8. Thermo-mechanical analysis of the NiTi Samples 1-3. Displacement $\Delta L$ and coefficient of thermal expansion (CTE) as a function of temperature (Displacement ( $\Delta L$, dotted curves, left $y$-axis) and coefficient of thermal expansions (CTE, solid line, right $y$-axis). Heating (bottom part of every curve) and cooling (upper part) were performed in the maximum range of -140 to $+150{ }^{\circ} \mathrm{C}$. Please note the different range of both $y$-axes for Sample 3.

In general, all three coating samples exhibited a reversible bending deflection during the thermal cycle. Forward (A-M) and reverse (M-A) transformations were recorded with approximately 10 to $30^{\circ} \mathrm{C}$ hysteresis common for NiTi [24,25]. However, although the martensitic transformation clearly starts at around $+60^{\circ} \mathrm{C}$ upon cooling, the transformation occurs in an extremely wide temperature region ranging from -70 to $+60^{\circ} \mathrm{C}$ and apparently depends strongly on the composition of the samples. This is most likely due to the partial heterogeneity of the microstructure (for instance, the somewhat inhomogeneous distribution of the austenitic grains across the thickness, Figure $6 \mathrm{c}$ ) and internal stresses between those layers [26,27].

\subsection{Functional Properties of Plasma Sprayed NiTi Coatings}

From the application point of view, it is important that the NiTi coatings have a good adhesion to the substrate and possess the functional properties, superelasticity or shape memory effect. The strain response of the samples was examined in three-point bending test at various temperatures from -50 to $+100{ }^{\circ} \mathrm{C}$ (Figure 9). 


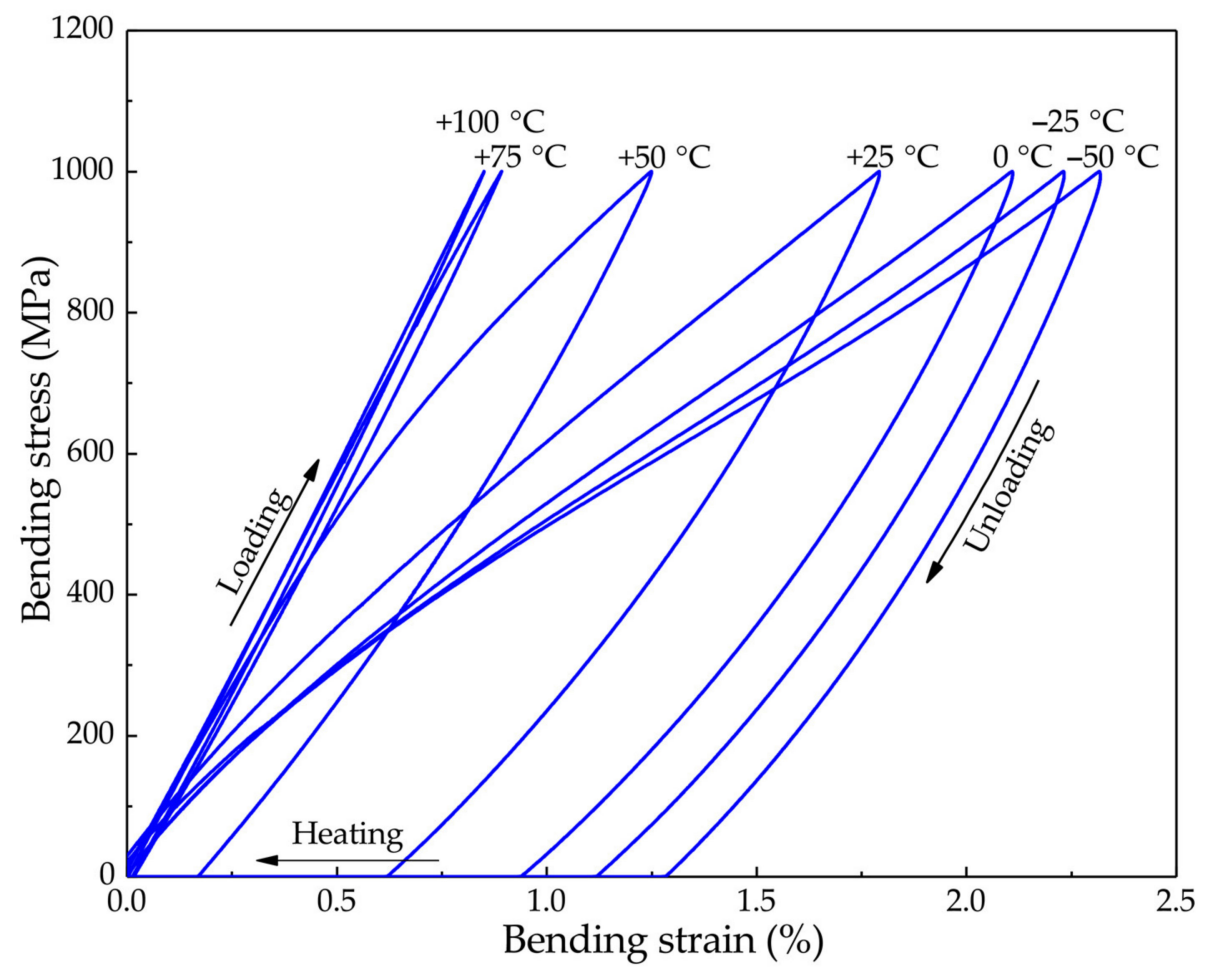

Figure 9. Shape memory effect demonstrated through bending stress-strain response of the plasma sprayed samples at different testing temperatures (Sample 3 shown).

The shape memory behavior was confirmed from the response of the samples. With the test temperature increasing above the room temperature, the stress-strain response stiffened and became pronouncedly linear, showing only a very limited hysteresis at $+100{ }^{\circ} \mathrm{C}$. This is because the stress required to induce the martensitic transformation in the surface layers increases with the increasing temperature. It is important to note that the presented values of the stresses in Figure 9 may be inaccurate in terms of absolute values as they are calculated from elasticity equations that are, strictly speaking, not applicable for a phase-transforming material. Nevertheless, the sharp change in the mechanical response with increasing temperature in the range from, e.g., +25 to $+75^{\circ} \mathrm{C}$ can be beneficially used in various applications.

In addition, three-cycle tensile tests of the dog bone-shaped samples were performed, involving loading and unloading at room temperature, followed by a stress-free heating to $100{ }^{\circ} \mathrm{C}$ (Figure 10).

The coatings exhibited a clear tendency toward strain recovery upon heating (about $0.4 \%$ of recovered strain). A changing stress-strain response during the three subsequent cycles suggested that a plastic deformation is also involved, and the reached maximum stresses are rather limited for NiTi [28-32]. This result would suggest that there is still a niche for further improvement of the NiTi coatings properties by further optimization of the RF-ICP spray conditions and parameters, including their microstructure and chemical and phase homogeneity and, consequently, their thermomechanical behavior. 


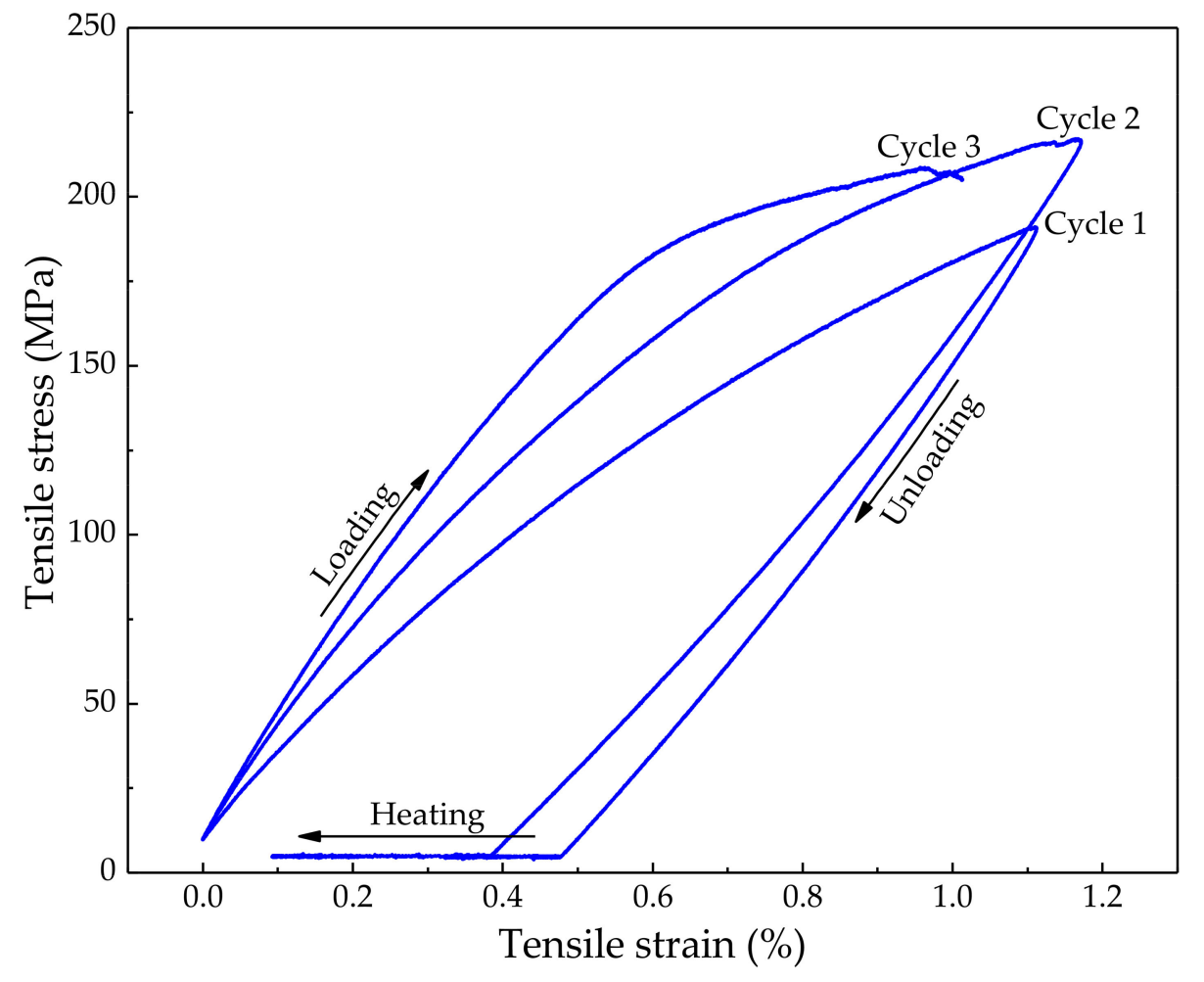

Figure 10. Tensile stress-strain response of the plasma sprayed NiTi (Sample 3 shown). The samples were deformed, unloaded, and heated to $100{ }^{\circ} \mathrm{C}$ in three consecutive steps tensile tests. In this sample, the third loading cycle led to a rupture.

Overall, the NiTi coatings prepared by RF-ICP process represent a combination of martensite and austenite as major, and intermetallic as minor phases, as confirmed by both XRD and EBSD analyses. The functional behavior of the plasma sprayed coatings was investigated by TMA, DMA, and cyclic tensile tests. TMA behavior shows that the displacement $(\Delta L)$ of the samples is a function of temperature. On cooling, the samples transform to the martensite phase, exhibiting the associated deformation. However, on heating, the samples return to the initial position, along with a phase change from martensite to austenite (Figure 8) that correlates with DSC findings from Figure 7. At room temperature, martensite is the dominant phase in the coatings (Table 3). This corresponds with the typical response of a martensite-phase NiTi shape memory alloy at room temperature observed from the bending and tensile response of samples [33]. The hysteresis response is more prominent towards lower temperatures $\left(\leq 50^{\circ} \mathrm{C}\right)$ with the unrecovered strain that correlates to the twinned martensite phase [34]. On loading, the twinned martensite NiTi shape memory alloy deforms to a detwinned martensite with the unrecovered strain upon unloading. On heating, the detwinned martensite transforms into austenite with the strain recovered (Figure 9, Figure 10). At high temperature $\left(>75^{\circ} \mathrm{C}\right)$, the sample shows a linear response, signifying an austenite phase (Figure 9).

\section{Conclusions}

Thick NiTi shape memory alloy coatings $(300-500 \mu \mathrm{m})$ were fabricated by radio frequency inductively-coupled plasma spraying from NiTi powders. At room temperature, the coatings contained a mixture of B2 cubic austenite and B19' monoclinic martensite phases. In terms of SMA-related properties, they exhibited a thermally induced $\mathrm{A} \leftrightarrow \mathrm{M}$ transformation at temperatures higher than those of the feedstock NiTi powders and a dependent mechanical response and shape memory effect in bending test, with strain recovery around $1.25 \%$. 
For the future work, further tuning the RF-ICP depositions conditions may be possible to obtain even higher-quality coatings. Aside from the spray parameters themselves, several other factors could be tuned, such as different rates of substrate cooling to control the phase composition and content of intermetallic phases.

Author Contributions: During the process of completing this paper, S.S. and P.Š. conceived and designed the study and wrote the manuscript. J.C. and J.K. (Jakub Klecka) performed the RFICP experiments, and J.C. wrote the manuscript. E.d.P. and F.L. performed XRD analysis. O.M. prepared the samples for SEM analysis. O.T. helped in TMA study as well analyzing the data. J.K. (Jaromír Kopeček) performed EBSD and EDX analysis. Z.W. performed the GD-OES analysis. L.H. helped in testing the functional properties. T.C. provided the RF-ICP facility. All authors have read and agreed to the published version of the manuscript.

Funding: This research was funded by Czech Science Foundation project 20-14114S, MEYS of the Czech Republic is acknowledged for the support of infrastructure projects CzechNanoLab (LM2018110), SOLID 21 (CZ.02.1.01/0.0/0.0/16_019/0000760) and ESS-participation of the Czech Republic-OP (CZ.02.1.01/0.0/0.0/16_013/0001794).

Institutional Review Board Statement: Not applicable.

Informed Consent Statement: Not applicable.

Data Availability Statement: The raw data used within this study could be obtained through a personal request to the corresponding author.

Conflicts of Interest: The authors declare that they have no known competing interests.

\section{References}

1. Otsuka, K.; Ren, X. Physical metallurgy of Ti-Ni-based shape memory alloys. Prog. Mater. Sci. 2005, 50, 511-678. [CrossRef]

2. Miyazaki, S.; Otsuka, K.; Suzuki, Y. Transformation pseudoelasticity and deformation behavior in a Ti-50.6at\%Ni alloy. Scripta Metall. 1981, 15, 287-291. [CrossRef]

3. Atli, K.C. The effect of tensile deformation on the damping capacity of NiTi Shape memory alloy. J. Alloy. Comp. 2016, 679, 260-267. [CrossRef]

4. Chluba, C.; Siemsen, K.; Bechtold, C.; Zamponi, C.; Selhuber-Unkel, C.; Quandt, E.; Miranda, R. Lima de. Microfabricated bioelectrodes on self-expanadable NiTi thin film devices for implants and diagnostic instruments. Biosens Bioelectron. 2020, 153, 112034. [CrossRef]

5. Cui, Z.D.; Man, H.C.; Cheng, F.T.; Yue, T.M. Cavitation erosion-corrosion characteristics of laser surface modified NiTi shape memory alloy. Surf. Coat. Technol. 2003, 162, 147-153. [CrossRef]

6. Zhou, Q.; Hayat, M.D.; Chen, G.; Cai, S.; Qu, X.; Tang, H.; Cao, P. Selective electron beam melting of NiTi: Microstructure, phase transformation and mechanical properties. Mat. Sci. Eng. A 2019, 744, 290-298. [CrossRef]

7. Liu, B.; Huang, S.; Chen, L.; Humbeeck, J.V.; Vleugels, J. Rapid synthesis of dense NiTi alloy through spark plasma sintering of a $\mathrm{TiH}_{2} / \mathrm{Ni}$ powder mixture. Mater. Lett. 2017, 191, 89-92. [CrossRef]

8. Novak, P.; Skolakova, A.; Pignol, D.; Prusa, F.; Salvetr, P.; Kubatik, T.F.; Perriere, L.; Karlik, M. Finding the energy source for self-propagating high-temperature synthesis production of NiTi shape memory alloy. Mater. Chem. Phys. 2016, 181, 295-300. [CrossRef]

9. Samal, S. Thermal plasma technology: The prospective future in material processing. J. Clean. Prod. 2017, 142, 3131-3150. [CrossRef]

10. Samal, S. Thermal plasma processing of materials: High temperature applications. Ref. Module Mater. Sci. Mater. Eng. 2020. [CrossRef]

11. Halter, K.; Sickinger, A.; Siegmann, S.; Zysset, L. Thermal Spray Forming of NiTi shape memory alloys. In SMST-2003: Proceedings of the International Conference on Shape Memory and Superelastic Technologies (SMST), Pacific Grove, CA, USA, 5-8 May 2003; SMST Society: Menlo Park, CA, USA, 2004; pp. 163-172.

12. Halter, K.; Siegmann, S.; Wielage, B. Vacuum plasma sprayed coatings and freestanding parts of Ni-Ti shape memory alloy. In Proceedings of the International Thermal Spray Conference (ITSC), Essen, Germany, 4-6 March 2002; pp. 357-361.

13. Klecka, J.; Cizek, J.; Matejicek, J.; Lukac, F.; Zlatnik, R.; Chraska, T. Tailoring the structure of RF-ICP tungsten coatings. Surf. Coat. Technol. 2021, 406, 126745. [CrossRef]

14. Weiss, Z. Calibration methods in glow discharge optical emission spectroscopy: A tutorial review. J. Anal. At. Spectrom. 2015, 30, 1038-1049. [CrossRef]

15. Dollase, W.A. Correction of intensities for preferred orientation in powder diffractometry: Application of the March model. J. Appl. Cryst. 1986, 19, 267-272. [CrossRef] 
16. Hill, R.J.; Howard, C.J. Quantitative phase analysis from neutron powder diffraction data using the Rietveld method. J. Appl. Cryst. 1987, 20, 467-474. [CrossRef]

17. Swain, B.; Mallick, P.; Bhuyan, S.K.; Mohapatra, S.S.; Mishra, S.C.; Behera, A. Mechanical properties of NiTi Plasma Spray Coating. J. Therm. Spray Tech. 2020, 29, 741-755. [CrossRef]

18. Sittner, P.; Sedlak, P.; Seiner, H.; Sedmak, P.; Pilch, J.; Delville, R.; Heller, L.; Kaderavek, L. On the coupling between martensitic transformation and plasticity in NiTi: Experiments and continuum based modelling. Prog. Mater. Sci. 2018, 98, 249-298. [CrossRef]

19. Samal, S.; de Prado, E.; Tyc, O.; Sittner, P. Shape setting in super-elastic NiTi ribbon. IOP Conf. Mater. Sci. Eng. 2018, 461, 012075. [CrossRef]

20. Kulkov, S.N.; Mironov, Y.P. Martensitic transformation in NiTi investigated by synchrotron X-ray diffraction. Nucl. Inst. Methods Phys. Res. A 1995, 359, 165-169. [CrossRef]

21. Prokoshkin, S.D.; Korotitskiy, A.V.; Brailovski, V.; Turenne, S.; Khmelevskaya, I.Y.; Trubitsyna, I.B. On the lattice parameters of phases in binary Ti-Ni shape memory alloys. Acta Mater. 2004, 52, 4479-4492. [CrossRef]

22. Duwez, P.; Taylor, J.L. The structure of intermediate phases in alloys of titanium with iron, cobalt, and nickel. JOM 1950, 2, 1173-1176. [CrossRef]

23. Mueller, M.H.; Knott, H.W. The crystal structures of $\mathrm{Ti}_{2} \mathrm{Cu}, \mathrm{Ti}_{2} \mathrm{Ni}, \mathrm{Ti}_{4} \mathrm{Ni}_{2} \mathrm{O}$, and $\mathrm{Ti}_{4} \mathrm{Cu} 2 \mathrm{O}$. Trans. Amer. Inst. Metall. Eng. 1963, 227, 674-678.

24. Samal, S.; Heller, L.; Brajer, J.; Tyc, O.; Kaderavek, L.; Sittner, P. Laser annealing on the surface treatment of thin super elastic NiTi wire. IOP Conf. Mater. Sci. Eng. 2018, 362, 012007. [CrossRef]

25. Zhang, J.; Cai, W.; Ren, X.; Otsuka, K.; Asai, M. The nature of reversible change in MS temperatures of Ti-Ni alloys with alternating aging. Mater. Trans. Jim. 1999, 40, 1367-1375. [CrossRef]

26. Hiraga, H.; Inoue, T.; Kamado, S.; Kojima, Y.; Matsunawa, A.; Shimura, H. Fabrication of NiTi intermetallic compound made by laser plasma hybrid spraying of mechanically alloyed powders. Surf. Coat. Technol. 2001, 139, 93-100. [CrossRef]

27. Halter, K.; Sickinger, A.; Zysset, L.; Siegmann, S. Low pressure wire arc and vacuum plasma spraying of NiTi shape memory alloys. In Proceedings of the International Thermal Spray Conference (ITSC), Orlando, FL, USA, 5-8 May 2003 ; pp. 589-595.

28. Jardine, A.P.; Field, Y.; Herman, H.; Marantz, D.R.; Kowalsky, K.A. Processing and properties of arc-sprayed shape memory effect NiTi. Scripta Metall. Mater. 1990, 24, 2390-2396. [CrossRef]

29. Samal, S.; de Prado, E.; Manak, J.; Tyc, O.; Heller, L.; Sittner, P. Internal stresses and plastic strains introduced into surface layers of bent NiTi ribbon by low temperature shape setting. In Proceedings of the International Conference on Shape Memory and Superelastic Technologies (SMST), Konstanz, Germany, 13-17 May 2019; pp. 100-101.

30. Kotnur, V.G.; Janssen, G.C.A.M. In situ stress measurements and mechanical properties of a composition range of NiTi thin films deposited at elevated temperature. Surf. Coat. Technol. 2012, 211, 167-171. [CrossRef]

31. Suresh, K.S.; Lahiri, D.; Agarwal, A.; Suwas, S. Microstructure dependent elastic modulus variation in NiTi shape memory alloy. J. Alloys Compd. 2015, 635, 71-74. [CrossRef]

32. Samal, S.; Molnárová, O.; Průša, F.; Kopeček, J.; Heller, L.; Šittner, P.; Škodová, M.; Abate, L.; Blanco, I. Net-Shape NiTi Shape Memory Alloy by Spark Plasma Sintering Method. Appl. Sci. 2021, 11, 2-16.

33. Otsuka, K.; Wayman, C.M. Shape Memory Materials; Cambridge University Press: Cambrige, UK, 1999 ; ISBN 9780521663847.

34. Birk, T.; Biswas, S.; Frenzel, J.; Eggeler, G. Twinning-induced elasticity in NiTi shape memory alloys. Shap. Mem. Superelast. 2016, 2, 145. [CrossRef] 